\title{
Research on the Impact of Big Data on Logistics
}

\author{
Yaxing Wang ${ }^{1, *}$, Lijie Feng ${ }^{1}$, Heyu Chang ${ }^{1}$ and $\mathrm{Min} \mathrm{Wu}^{1}$ \\ ${ }^{1}$ School of management and engineering, Zhengzhou University, China \\ Corresponding Email:615871159@qq.com
}

\begin{abstract}
In the context of big data development, a large amount of data will appear at logistics enterprises, especially in the aspect of logistics, such as transportation, warehousing, distribution and so on. Based on the analysis of the characteristics of big data, this paper studies the impact of big data on the logistics and its action mechanism, and gives reasonable suggestions. Through building logistics data center by using the big data technology, some hidden value information behind the data will be digged out, in which the logistics enterprises can benefit from it.
\end{abstract}

\section{Introduction}

With the rapid popularization of the Internet and the Internet of things, information technology has brought the rapid growth of data scale, all walks of life will produce massive data in the process of operation. If you can not use the massive data effectively, the data will become a drag on the industry, into a data swamp. Technology application of big data is a kind of technical behavior by searching, calculation, analysis, storage, index, query complex structure, large quantity, changeable type and highly commercial value of the collection of data set. Big data applications bases on massive facts, we can use scientific methods to tap the potential value of data, make the mass of data into a new type of intellectual resources, prompte the traditional industry to change the way of thinking, use the data of this important factor in production better, create more benefits for society.

In this era of big data, there will be a lot of data in the logistics industry every day, especially the whole logistics, including transportation, warehousing, transportation, distribution, packaging and other links [1]. Each link to each other forms a complete information flow. If the logistics enterprises can not accurately process these data timely, then it will bring the logistics enterprise a data disaster and waste of resources. In recent years, a large number of domestic and foreign experts focus on the application of big data in the logistics industry. It is of great significance for enterprises to adapt to the changeable market environment and to deal with the fierce market competition. Also it will have a significant impact on the logistics industry's strategic decision-making, operational management, brand management, customer relationship management, service innovation and so on. This helps enterprises to optimize the allocation of logistics resources, accelerate the upgrading and transformation of the logistics industry, to meet the requirements of the information age [2]. In the context of large data, the logistics industry needs to seize the opportunity to improve the ability, use data resources, improve efficiency, in the market competition advantage.

\section{Definition and characteristics of big data}

Now, the concept of big data does not have a unified view. The contemporary society is an information and digital society.The information data is produced quickly, flows, in all kinds of information source, information platform, 
information channel, information terminal.In all,the data is filled with the whole world. The number of data is not only increasing in exponential form but also the structure of the data tends to be more complicated. This makes the big data has a different connotation compared with the previous data. McKinsey Global Research points out that, "Big data" is a large collection of data, greatly beyond the traditional database software tools in the ability to access, storage, management, analysis [3]. It is a way of decision making based on data driven [4],In a short period of time to quickly carry out data collection, storage, analysis, collation through the network platform. "Big data" is usually used to describe a large number of unstructured and semi-structured data created by a company. These data will cost too much time and money when they are downloaded to the relational database for analysis. Therefore, the strategic significance of "big data" technology does not lie in the master of the huge data information, and lies in the meaning of these data for professional processing, that is, from the "big data" mining of "small data".

At present, the more unified understanding is that: big data has four basic characteristics: huge data size, various data types, high data processing speed, low value of the data. These four characteristics make big data is different from the massive data". Huge data scale is the basic attribute of big data. Data size is large, on the one hand, because the data has a wide source, access to a wide range of channels. On the other hand, in order to make the description of the data closer to the original thing and thus lead to the proliferation of data. The reason for a wide variety of data mainly refers to the information age needs to pay attention to the dimensions and types of data have increased significantly. At the same time, focusing on the research and analysis of unstructured data which contains a large number of details of the information reserves space for personalization. Data processing is faster owing to the data generating speed, high speed of communication, but also for the timeliness of consideration. At the same time, we can explore the potential effective value, after eliminating the redundant data, invalid, no value data by fast processing. Low data value density is an important attribute of the unstructured data which is concerned by big data. Big data retained the original data, get all the details of things without abstraction and induction. Directly using the original data and all the data, you can analyze more information, but at the same time it also cited a large number of no sense and even the wrong information. Therefore, relatived to the specific application, the proportion of useful information of non structured data is very low, and the value density is also low.

Big data technology is a new technology, it brings opportunities to the logistics enterprises, but also brings challenges. Using big data technology scientifically and reasonably will play a positive role in promoting the management and decision-making, resource allocation and other aspects of logistics enterprises. If we compare big data to an industry, then the key to achieve profitability of this industry is to improve the data processing capacity and achieve value-added through the processing data. Therefore, in the background of big data, data information has become an important factor in production. This will change the way of management of logistics enterprises and innovation of the profit mode of logistics enterprises.

\section{Big data helps to make scientific decision of logistics}

The core of large data is finding and prediction. Through mining and analysis data, find the running law of history hidden under the data surface, and predict the future trend. Therefore, under the background of "big data", data information has become an important production factor, which will change the management mode of logistics enterprises and innovate the profit mode of logistics enterprises [5]. In the process of using large data assets, each step like acquisition, integration, governance, analysis, prediction, scientific decision-making to take precise action, plays an important role. Making decisions based on big data is a major highlight of the 2015 electricity suppliers logistics enterprises. Big data is variable, the algorithm is the rule, set what kind of rule will receive what kind of results. Take the "Rookie Network Technology Co., Ltd." (herein after referred to as the rookie network) as an example. Before the "double eleven" in 2015, this company analyzed the historical data of commercial tenant taking part in "double eleven" in recent four years which includes the location, previous orders and logistics of commercial tenant, and predicted the situation for 2015 according to the zone, and shared the predicting network sending and receiving information with information of each express enterprise. Each express logistics enterprise combined with three important nodes - warehousing, trunk and distribution of 
logistics system construction to deploy the corresponding logistics facilities according to these forecasts. More accurate data analysis and prediction make the courier company be more accurate and easy in response. The application of big data technology effectively reduces procurement, warehousing, internal logistics distribution share and finally expects to achieve zero stock, zero distance, zero freight [6].

\section{Analysis of the impact of big data on the logistics industry}

The strategic significance of big data technology lies in the professional processing of information and the value mining, and analysis of the long-term trends in the market and so on. With the gradual deepening of the application of large data in logistics industry, the data obtained in the future logistics industry is not only the industry's internal information, but also includes a large number of external information. Based on the data analysis, the logistics enterprises can tailor personalized and differentiated service for each customer with forecast.

Big data analysis can help logistics enterprises understand the industry development. At present, the logistics enterprises are faced with a highly competitive and rapidly changing market environment, many transportation load problems is in virtue of logistics enterprises lacking prediction of future market through data analysis, and they blind to increase transport capacity and storage area when they only see the immediate business growth. There will be a large number of surplus capacity and vacant warehouses when the market shrinks and the business volume declines, which will lead to the loss of logistics enterprises. Through the analysis of large data, logistics enterprises can make certain predictions on the future market and the behavior of competitors, timely adjust the development strategy and avoid blind asset investment, thus reduce losses.

Big data analysis can help logistics enterprises to enhance customer loyalty. For logistics enterprises, the analysis of customer's behavior habit can make their market promotion investment, supply chain investment and promotion investment returns be maximization. Through advanced statistical methods, the logistics enterprise can establish model through the historical record and analysis of users, predict their future behavior, then design a forward looking logistics service plan, therefore integrate resources and improve the level of cooperation with the customer to avoid the loss of customers. Logistics enterprises can not only mining value of existing users through large data, but also access new users efficiently through the data. Big data technology is changing the game rules in the market promotion with revolution. Through the promotion of information interaction, push service adjustment, price changes and market changes and other information to customers, and constantly meet the change of customer needs. In the context of the Internet, marketing will not be affected by time and place restrictions, and is no longer just a one-way flow of information. The great difference is that from contacting with customers and attracting customers to manage customers, launch promotions and finally to reach a sale, the entire marketing process can be realized only in the information interaction, and carry out precision marketing through the understanding of user behavior.

Big data analysis can improve the transparency and quality of service management of logistics industry. Big data analysis can make the logistics practitioners and the performance of the logistics organization be more transparent through the logistics information communication opening and information sharing, and indirectly promote the improvement of logistics service quality. According to the operation and performance data set by logistics service providers, the data can be analyzed and establish visualized flow chart and dashboard, and promote information transparency. There are world famous logistics enterprises are currently testing the instrument panel, see it as a part of the construction of active, transparent, open, collaborative companies. Opening logistics quality and performance data can help customers make more informed decisions, which will also help the logistics service provider to improve overall performance, finally enhance the competitiveness.

Big data analysis can optimize the profit mode of logistics enterprise. Through establishing the network platform of logistics industry and the community, the platform can produce a large number of valuable data, provide valuable data and summary the consumption records of logistics industry customers, and carry on the advanced analysis, and ultimately improve the decision-making ability of logistics demand side and logistics service provider. Data analysis of users on the platform is updated in real time to ensure that behavior prediction of users is always in line with the actual needs of 
users. At the same time, design some market strategy according to the behavior forecast dynamically, market expansion speed will depend on the developing speed of the big data acquisition and analysis in logistics industry. Establish a national customer database to provide accurate and timely logistics information consult, which will significantly improve the company's visibility and profitability.

\section{Suggestions and measures}

\subsection{Paying enough attention to big data at the national level}

The state should conform to the requirements in the era of big data, provide strong support to big data technology in terms of policy-making and resource input in the logistics industry, eliminate information barriers, concentrate forces to establish a healthy ecological environment of big data and attache great importance to big data theory and application as well as its safety. Furthermore, developing a long-term plan on a macro level and constructing a data sharing information platform.

\subsection{Coordinating all kinds of logistics way and building a three-dimensional logistics network}

The logistics industry should strengthen relation with various modes of transport, integrate transportation platform, coordinate different transport modes, adjust the network structure, strengthen the effective connection of various modes of transportation. Logistics enterprises should make full use of existing information infrastructure to integrate information resources and set up a modern logistics information processing platform in terms of railway, highway, aviation, shipping and and so on. In the aspect of construction of information platform, they also should pay attention to information system standardization and sharing in order to construct cross-platform, collect mechanism of multi-level information resources and create seamless information chain. Besides, the government needs to pay attention to traffic and logistics planning, improve the comprehensive transportation system and optimize logistics spatial layout.

\subsection{Combing cloud logistics and big data and improving the logistics efficiency}

In order to set up a good information platform, the logistics enterprises should speed up the logistics infrastructure standardization, informatization and intelligent hardware and software construction because the application of cloud logistics and big data is inseparable from the existing logistics information platform [7]. From a demand view, enterprises can have a complete data life cycle control through analyzing and integrating the data information which is corrected and extracted from the big data system. Furthermore, the complete logistics information platform can gather big data information and make both supplier and buyer to enhance mutual understanding. The supplier and buyer can get a full range of logistics services such as sharing information, making agreement and integrating logistics solution plan by using logistics management platform. Besides, combining cloud logistics and big data can also innovate logistics development mode and thus improve the logistics efficiency.

\section{Conclusion}

As a new technology, big data will bring both opportunity and challenge to logistics enterprises because its application transformed logistics enterprises from traditional logistics to data logistics and network logistics, and gradually developed into the cloud logistics. In the future, the application of mobile terminal logistics will be expanded and at that time, it will generate the larger data sets. So proper, efficient application of big data technology will play a positive role for logistics enterprises in terms of management and decision-making, customer relationship maintenance and resource allocation

Logistics enterprises will eventually become the data-driven enterprises, and it is a necessary condition for the further development of the enterprises in the era of big data. In the face of this opportunity, I call on all senior managers in 
logistics enterprises should give great attention to the big data, squarely face the problems of its application, properly apply big data to business management and bring greater benefits for the enterprise.

\section{References}

1. Tian Xue, Si Weipeng, Liu Yingying. The application of big data in the logistics enterprises. Electronic Commerce,2015(1):36-37.

2. He Jun. The impact of big data in enterprise management decision. Scientific and Technological Progress and Countermeasures, 2014(4):65-68.

3. James Manyika, Michael Chu. Big Data: The Next Frontier for Innovation, Competition and Productivity. McKinsey Quarterly, 2011(5):27-30.

4. Yan Xiaofeng, Zhang Dexin. Big data research. Computer Technology and Development, 2013(4):168-172.

5. Zi Wucheng. The Evolution of the Era of "Big Data" Enterprise Ecosystem and Construction. Social Science, 2013(12):55-62.

6. Xiang Meiying. Zero Inventory Management Analysis. China Market, 2009(45):27-28.

7. Han Zhaolong. Modern Logistics Industry Development in the Era of Big Data. Quality of Goods and Theory Research,2014. 